\title{
A Sociedade Civil no Direito Internacional Humanitário
}

\author{
The Civil Society in International Humanitarian Law
}

\author{
Gustavo Oliveira Vieira ${ }^{1}$ \\ Pedro Horta ${ }^{2}$ \\ Igor Fischer ${ }^{3}$
}

\begin{abstract}
Resumo: O presente artigo discute o papel da atuação da sociedade civil no Direito Internacional Humanitário, especificamente no monitoramento e na influência sobre os Estados para que participem da formulação e se alinhem aos desafios humanitários das novas fontes de Direito Internacional Humanitário, em específico, da Convenção sobre Munições Cluster. O problema da pesquisa diz respeito ao papel da Sociedade Civil Global perante o Direito Internacional em favor da erradicação de armas que geram danos inaceitáveis contra civis. Para tanto, a partir da perspectiva dialética, utilizar-se-ão abordagens críticas do Direito Internacional que compreendem o caráter da sociedade civil de potencial agente emancipatório. Para isso, o presente trabalho é desenvolvido em duas partes, inicialmente sobre as abordagens sobre segurança e direito internacional, depois acerca da atuação da Sociedade Civil Global no desarmamento humanitário.
\end{abstract}

Palavras-chave: Desarmamento Humanitário. Direito Internacional. Sociedade Civil Global. Munições Cluster.

\begin{abstract}
This article discusses the role of civil society's action in International Humanitarian Law, particularly at the monitoring and influence on states to both participate at the formulation and align themselves at the humanitarian challenges of the new sources of Humanitarian International Law, in this regard, the Convention on Cluster Munitions. The issue of this research concerns the questioning about the potential and effective role of the Global Civil Society towards International Law aiming the elimination of weapons that generate unacceptable damage against civilians. In this regard, from the dialectical perspective, we will use critical approaches of International Law that understand the civil society's potential emancipatory character. For this
\end{abstract}

\footnotetext{
1 Professor do bacharelado e do mestrado em Relações Internacionais da Universidade Federal da Integração Latino Americana (UNILA/PR). Doutorado, Mestrado e Bacharelado em Direito pela Universidade do Vale do Rio dos Sinos (Unisinos). Fez doutorado sanduíche junto à University of Manitoba/Canadá, com bolsa ELAP.

${ }^{2}$ Bacharelando em Relações Internacionais na Universidade Federal da Integração Latino Americana (UNILA/PR). Atuou no projeto de extensão "Desarmameto Humanitário: abordagem política" e desenvolveu iniciação científica sobre o tema.

3 Bacharel em Relações Internacionais pela Universidade Federal da Integração Latino Americana (UNILA/PR). Atuou em projeto de extensão "Desarmamento Humanitário: abordagem política" e desenvolveu iniciação científica sobre o tema. Trabalha (2019) como assistente de campo para acolhimento de migrantes em Roraima.
} 
purpose, this paper is developed in two parts. Firstly, it concerns a few security studies and international law approaches. Secondly, it debates the Global Civil Society action in humanitarian disarmament.

Keywords: Humanitarian Disarmament. International Law. Civil Society. Cluster Munitions.

\section{Introdução}

A adequada compreensão dos movimentos que orientam o Direito Internacional passa por um estudo atento das Relações Internacionais e seus centros decisórios, in casu, a diplomacia oficial, que na última quadra da história experimenta a inclusão de novas pautas, humanizando seus conteúdos, e de novos atores, como a sociedade civil global, com vistas a dialogar mais democraticamente com os membros das sociedades civis dos Estados. É no fluxo destas transformações, no Direito Internacional, nas Relações Internacionais e na diplomacia que o presente artigo pretende registrar os desafios do Direito Internacional do Desarmamento Humanitário, que tem na sociedade civil um dinamizador político relevante, construindo o que alguns pesquisadores vão denominar de "nova diplomacia", "novo multilateralismo", "nova governança global” (CAMERON, LAWSON, TOMLIN, 1998; WILLIAMS, GOOSE, WAREHAM, 2008).

A construção histórica do Direito Internacional nos últimos séculos o fez centrado à regulação das relações interestatais, com vistas à estabilização da interação entre as pessoas jurídicas de Direito Internacional originárias e à prevenção da guerra, sem tanto espaço à inclusão dos povos e de suas garantias. Ou melhor, os povos sempre mediados pela atuação dos Estados. Gradualmente, alguns ramos do Direito Internacional se desenvolvem para proteger e promover direitos dos povos (autodeterminação, por exemplo), de coletividades de indivíduos (como o Direito Internacional do Trabalho) e dos indivíduos (pelo Direito Internacional dos Direitos Humanos, dos Refugiados, Consumidores, entre 
outros), como é o caso, também, da expansão normativa do Direito Internacional Humanitário.

O Direito Internacional Humanitário, sinônimo de Direito Internacional dos Conflitos Armados, é um ramo do Direito Internacional Público que estabelece limitações aos meios e métodos de guerra e determina mecanismos de proteção dos não combatentes (SASSÒLI; BOUVIER, 1999, p. 67). É um ramo especial do Direito Internacional dirigido às situações de conflitos armados que procura mitigar os efeitos da guerra, "em primeiro lugar limita a escolha dos meios e métodos para conduzir as operações militares, e, em segundo lugar, obriga os beligerantes a não agredir as pessoas que não estejam ou não mais estejam participando das ações hostis" (HAUG, 1993, p. 492).

A partir dos êxitos realizados no marco do Tratado sobre Erradicação de Minas Terrestres Antipessoal de 1997 (VIEIRA, 2006), criouse um referencial de atuação da sociedade civil global. Novos movimentos foram articulados e redundaram em novas fontes de Direito Internacional, como no que se tornou conhecido como Desarmamento Humanitário - por não servir a objetivos estratégicos como outras tratativas na área, e focar na mitigação dos impactos humanitários, tendo aporte político determinante na Sociedade Civil Global (notadamente pela atuação da ICBL). Nesse fluxo, destacam-se, além do Tratado de Erradicação de Minas Antipessoal, a Convenção sobre Munições Cluster de 2008, o Tratado sobre Comércio de Armas de 2013 e o Tratado sobre a Proibição de Armas Nucleares de 2017.

Cabe destacar que se entende por Sociedade Civil Global, enquanto plataforma composta de uma pluralidade de agentes que discutem, advogam e negociam temas e ajustes que irão moldar os desenvolvimentos globais (KALDOR, 2003, p. 590), apresenta, ao atuar por pautas como a crise ecológica (Greenpeace) os Direitos Humanos (Anistia Internacional, Human Rights Watch , Conectas Direitos Humanos) e o Desarmamento 
Humanitário (ICBL, Control Arms, ICANW), potenciais emancipatórios a serem levados em consideração.

Com isso em mente, o problema desta pesquisa diz respeito ao papel potencial e efetivo da sociedade civil global perante o Direito Internacional, à luz do caso de sua atuação no Direito Internacional do Desarmamento Humanitário. Para tanto, a primeira parte do texto irá apresentar algumas abordagens críticas de Relações Internacionais e do Direito Internacional para, na sequência, evidenciar como a humanização destes campos instrumentalizam conceitos paradigmáticos que constituem eixos emancipatórios da sociedade civil no cenário pós-nacional. Em seguida será apresentada a temática do desarmamento humanitário, bem como trará o problema da produção e exportação brasileira dessas armas que produziram vítimas no Iêmen. A partir daí, a terceira parte do artigo trará alguns dados acerca da atuação da sociedade civil que culminou em alguns tratados.

\section{Abordagens (críticas) de Direito Internacional e Segurança}

Tanto o Direito Internacional quanto o entendimento acerca da Segurança Internacional se identificaram historicamente pelo estatocentrismo, em um padrão que não abrange de modo suficiente e pragmático pautas sobre questões sociais, culturais e específicas de grupos e indivíduos vulneráveis - especialmente os atores, povos e indivíduos marginalizados da política internacional. O entendimento sobre Segurança caracterizou-se até o fim da Guerra Fria pela ausência de sensibilidade às comunidades política e economicamente periféricas, em grande parte, pela maneira com que se compreendiam as Teorias Realistas das Relações Internacionais, sintetizados nos chamados quatro 'S': States, Strategy, Science and Status quo (WILLIAMS, 2008). De maneira semelhante, o Direito Internacional permaneceu na maior parte de sua existência 
extremamente ocidental, elitista, androcêntrico e imperial (RAJAGOPAL, 2003).

As mudanças nas dinâmicas internacionais convergiram, nos anos 1990, em um período de agitação e reinterpretação de diversos aspectos das Relações Internacionais. Dentre os fatos e tendências observados com o fim da Guerra Fria, destacam-se: o fortalecimento dos regimes de Governança, inclusive na área de Segurança, sob o enfoque da segurança humana; o crescimento da importância do Direito Internacional e dos Direitos Humanos; e a emergência da Sociedade Civil Global (BALLESTRIN, 2010) elementos que demarcam o fortalecimento de valores humanitários na esfera internacional e da própria humanização das Relações Internacionais.

Tais mudanças refletem na ampliação e aprofundamento do entendimento sobre Segurança, exemplificados pelo surgimento do conceito de Segurança Humana e de Escolas críticas como a de Aberystwyth (Gales), permitindo a entrada de novas agendas e atores em foco para além do âmbito exclusivamente militar. Ademais, pode também ser percebido o surgimento de novas abordagens do Direito Internacional que levassem em conta e buscassem a emancipação dos sujeitos subalternizados, a exemplo das "Abordagens do Terceiro Mundo ao Direito Internacional" (Third World Approaches to International Law - TWAIL), que aparecem em 1997, e ainda são pouco pautadas pela maioria dos internacionalistas (GALINDO, 2013).

\subsection{Convergência das Abordagens Críticas de Relações Internacionais e Direito Internacional}

Tendo como um de seus principais expoentes Ken Booth, a Escola de Aberystwyth também se opõe ao realismo e ao positivismo, trazendo uma forte agenda política e emancipatória com o objeto referencial transferido do Estado para o indivíduo (DIAS et al, 2011). Na obra Security and 
Emancipation (1991), Booth critica o estatocentrismo da Segurança, afirmando que:

\begin{abstract}
It is illogical to place states at the centre of our thinking about security because even those which are producers of security (internal and external) represent the means and not the ends. It is illogical to privilege the security of the means as opposed to the security of the ends. (...) It is appropriate to place emancipation at the centre of new security thinking in part because it is the spirit of our times (BOOTH, 1991, p. 320-321).
\end{abstract}

Desse modo, entende Segurança como a ausência de ameaças, e emancipação como libertação das pessoas - como indivíduos ou grupos -, dos constrangimentos físicos e humanos que os impedem de fazer o que livremente escolherem. Portanto, compreende a guerra e sua ameaça como um desses constrangimentos, mas soma a eles questões como pobreza, opressão política, educação precária etc. Segurança e Emancipação são, portanto, dois lados de uma mesma moeda (BOOTH, 1991, p.319).

Quanto à questão emancipatória, as "Abordagens do Terceiro Mundo ao Direito Internacional" (Third World Approaches to International $L a w-T W A I L)$ trazem problematizações e argumentos importantes. Tendo o termo sido cunhado em 1997, e ainda sendo pouco pautado pela maioria dos internacionalistas, é, segundo Mutua (2000), uma abordagem reativa em relação ao imperialismo intrínseco ao Direito Internacional, e proativo por buscar transformações, em especial para o Terceiro Mundo. O autor critica o Direito Internacional tradicional por sua pretensão de universalidade em contraste com o fato de ter a Europa como centro, o cristianismo como base da civilização, o capitalismo como inato do homem e o imperialismo como necessidade (MUTUA, 2000).

As TWAIL são, portanto, reações problematizadoras do Direito Internacional estatocêntrico, ocidental, elitista e imperial (RAJAGOPAL, 2003). Apesar de se observar contradições e divergências internas, apresentam em comum uma postura de questionamento ao Direito Internacional e às injustiças da ordem global em relação a aspectos que afetam o Terceiro Mundo, buscando seu empoderamento. Além disso, são 
contrários à construção hierárquica do Direito Internacional, que caracteriza também sua instrumentalização ao longo da história (MUTUA, 2000).

Em tais abordagens teóricas tratam, sobretudo, de problematizar as consequências da desigualdade estrutural das Relações Internacionais, da sociedade mundial, sobre o Direito Internacional, ou, como delineia Rémi Bachand (2018), de problematizar os subalternos no Direito Internacional a partir de uma crítica política. E, ao se considerar isso, é inevitável fazer emergir um conjunto de críticas sobre o que e quem o Direito Internacional tem representado, ou seja, como as estruturas hegemônicas dos países ditos centrais se manifestam, fazendo coro aos devidamente empoderados na lógica do capitalismo de seus países, e como as subalternidades são sistematicamente ocultadas no sistema.

Um dos principais temas presentes nessa abordagem é a perspectiva da resistência, notadamente quando se desvela que o Direito Internacional tem sido perpetuador das relações de dominação coloniais, sendo, portanto necessária uma abordagem distinta, de resistência e de crítica, que atenda de forma prática e empírica princípios como igualdade e paz. Afirma-se, com isso, a necessidade de pensar o Direito Internacional como espaço também de resistência e emancipação, de subversão das hierarquias, de modo que tanto Estados terceiro-mundistas quanto indivíduos e movimentos sociais se tornem agentes nesse processo (GALINDO, 2013).

Nesse sentido, Mutua (2000) apresenta três objetivos comuns que identificam esse movimento: 1) desvelar a instrumentalização do Direito Internacional com origens eurocêntricas como perpetuador de uma lógica hierárquica e subordinadora dos demais países; 2) construir uma estrutura normativa alternativa para guiar a governança internacional; 3) buscar políticas de erradicação do subdesenvolvimento do Terceiro Mundo. Tais elementos permitem perceber uma ligação entre teoria e prática presente nas TWAIL. De certo modo, a abordagem das TWAIL permitiria uma 
problematização qualificada sobre a natureza realista das Relações Internacionais e o viés idealista do Direito Internacional.

É com vistas a problematizar os desafios do sistema jurídico-político internacional que novos paradigmas e conceitos têm emergido no marco da humanização destas pautas, tradicionalmente estratégicas e estatocêntricas.

\subsection{Humanização do Direito Internacional e das Relações Internacionais}

As abordagens críticas de Relações Internacionais e do Direito Internacional emergem pari pasu a um conjunto de novos conceitos operacionais que tratam de incluir a dimensão humana nas pautas, portanto materialmente, e nos processos, enquanto atores. Isso ocorre no fluxo da construção das ressignificações trazidas pela Humanização das Relações Internacionais e do Direito Internacional (DUPUY, 2002, p. 416), evidenciados nos conceitos de desenvolvimento, direito e segurança, que, na medida em que são adjetivados com o vocábulo "humano" redefinem seus indicadores, seus valores e objetivos, como Direitos Humanos, Desenvolvimento Humano e Segurança Humana.

As três vertentes da proteção internacional da pessoa humana, Direito Internacional dos Direitos Humanos, Direito Humanitário e Direito dos Refugiados, constituem em uma convergência pela proteção do ser humano em qualquer contexto. Nisso, a expansão normativa constituída pelo farol dos Direitos Humanos, por tratados universais e regionais, com aparatos de implementação que incluem mecanismos de responsabilização internacional dos Estados em caso de violação dos Direitos Humanos, gerou novos eixos axiológicos e conceituais à organização da vida nos Estados Democráticos de Direito. Trata-se de uma nova gramática que fazem o Direito transitar da tradição burguesa de proteção da propriedade para proteção do bem estar dos hipossuficientes. 


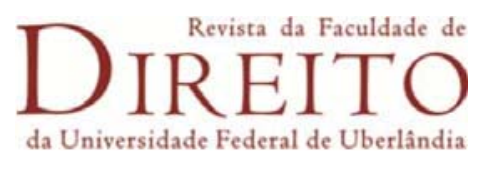

É da demanda por novas perspectivas nas Relações Internacionais e no Direito Internacional que surge a abordagem de segurança humana, como relata o professor Cançado Trindade:

[...] the UNDP (United Nations Development Programme) focused on the new dimensions of human security as a universal concern: the concept of security is no longer related to the territory of nationStates, but rather to people, to their legitimate concerns in their daily lives (e.g., protection from the threats of hunger, disease, unemployment, crime, social conflicts, political repression, environmental hazards). It further pointed out that the paradigm of the concept of sustainable human development values human live for itself, rather than wrongfully seeing human beings as merely the means of producing material goods. The quality of human life is an end in itself, which takes into account all human rights (economic and social and cultural as well as civil and political) (CANÇADO TRINDADE, 2006a, p. 369).

O conceito de Segurança Humana surge no Relatório do Programa das Nações Unidas para o Desenvolvimento (PNUD), de 1994, e tem relevância para esta análise por transferir o foco dos Estados para os indivíduos, passando a englobar elementos para além dos militares, tais como Segurança econômica, alimentar, sanitária, ambiental, pessoal, comunitária e política. Este relatório reforça uma crítica à ideia de Segurança hegemônica até então, afirmando que:

El concepto de seguridad se ha interpretado en forma estrecha durante demasiado tiempo: en cuanto seguridad del territorio contra la agresión externa, o como protección de los intereses nacionales en la política exterior o como seguridad mundial frente a la amenaza de un holocausto nuclear. La seguridad se ha relacionado más con el Estado-nación que con la gente. (PNUD, 1994, p. 25)

Nesse sentido, apresenta dois aspectos principais: freedom from fear, referente à proteção das pessoas em relação a ameaças tais como guerras, conflitos, violência e genocídios; e freedom from want, que leva em conta ameaças dentre as quais se enquadram fome, doenças e questões ambientais (PNUD, 1994). Se em um primeiro momento as questões de Desarmamento se enquadram no primeiro enfoque, a Escola crítica de Aberystwyth (Gales) 
permite relacioná-las ao segundo ponto ao associar Segurança à emancipação do indivíduo.

É nesse sentido, percebendo na Segurança e no Direito Internacional potenciais espaços e mecanismos emancipatórios, que pretende-se compreender a importância da Sociedade Civil Global, em sua acepção ativista, através de sua inserção nos processos de Desarmamento Humanitário, como capaz de influenciar na criação de normas que regulam ou proíbem o comércio, fabricação, armazenamento e uso de determinados armamentos. Tais armamentos são vitimizadores, majoritariamente, de populações civis do Sul global, reforçando seu subdesenvolvimento e restringindo sua emancipação.

\section{Sociedade Civil Global pelo Desarmamento Humanitário: novo multilateralismo em curso(?)}

A novidade constituída pela inclusão da Sociedade Civil Global enquanto ator nas tratativas sobre pautas humanitárias do desarmamento e controle de armas indica a formação de um novo multilateralismo, inclusivo de novos atores, até então excluídos da construção da esfera político-jurídica internacional. Para desenvolvermos o argumento, inicialmente definir-se-á o Direito Internacional Humanitário, e seu desdobramento, o Direito Internacional do Desarmamento Humanitário, com aprofundamentos sobre o conceito de Sociedade Civil Global.

\subsection{Direito Internacional Humanitário}

O Direito Internacional Humanitário que emerge no final do século XIX, com o objetivo de mitigar o sofrimento causado pelas guerras. A primeira Convenção de Genebra de 1864 que trata do direito da guerra, jus in bello: "conjunto de normas que floresceram no domínio do direito das gentes quando a guerra era uma opção lícita para resolver conflitos entre 
Estados” (REZEK, 2016). Del'Olmo (2006), define o Direito Internacional Humanitário como “a reunião de postulados, normas e condutas, jurídicas ou não, empreendidas pelos seres humanos buscando a diminuição dos danos provocados pela guerra" que, diferentemente do jus in bello, tem um enfoque muito maior nos indivíduos que estão sujeitos a danos físicos causados pela guerra, e busca remediar esta situação.

O Direito Internacional Humanitário ocupa-se em limitar o uso da violência em conflitos armados, poupando aqueles que não participam (civis) ou não mais participam (prisioneiros de guerra ou combatentes feridos ou doentes) diretamente das hostilidades, limitando a violência ao montante necessário para alcançar os objetivos do conflito, que pode ser independentemente das causas da batalha - apenas para enfraquecer 0 potencial militar do inimigo (SASSÒLI; BOUVIER, p. 67).

Em conformidade ao Direito Internacional Humanitário, denominou-se, em 1907, o Direito de Haia, onde se regula a guerra propriamente dita, estabelecendo os direitos e deveres dos contendores durante as operações bélicas colocando limites nessas ações (DEL'OLMO, 2006), e onde sobrevivem normas limitativas da liberdade de ação dos beligerantes, as quais Rezek alega que ainda são úteis nos conflitos armados que ameaçam o ideal pacifista das Nações Unidas. Elas têm três princípios:

(a) o dos limites ratione personae (os não combatentes serão poupados de qualquer ataque ou dano intencional); (b) o dos limites ratione loci (os lugares atacáveis são somente aqueles que configuram objetivos militares, cuja destruição total ou parcial representa para o autor do ataque uma clara vantagem militar); e (c) o dos limites ratione conditionis (proíbem-se as armas e os métodos de guerra capazes de ocasionar sofrimento excessivo aos combatentes inimigos) (REZEK, 2016, p. 440 - grifos no original).

Assim, o Direito de Haia regulamenta os meios que causam danos desproporcionais às necessidades militares, como atingir um inimigo já sem condições de se defender, destruir propriedade do país antagonista, coagir nacionais de um Estado a lutar contra sua própria pátria, saquear povoações e atacar cidades ou construções desse Estado que estejam sem condições de 
defesa. Isto posto, é cabível de se pressupor que também há, nos postulados do direito de Haia, uma busca pelo desarmamento, uma busca da limitação dos meios de destruição e uma freada na criação e na fabricação de armas.

Ressalte-se, também, a diferença entre Direito Internacional Humanitário e Direito Internacional dos Direitos Humanos, onde este último se destina a proteger o ser humano na paz e o primeiro tem o seu campo de aplicação por ocasião dos conflitos armados, mas "convergem na realização do propósito comum de proteger o ser humano em tempos de paz assim como de conflitos armados, em seu próprio país assim como alhures, em suma, em todas as áreas da atividade humana e em todas e quaisquer circunstâncias" (CANÇADO TRINDADE, 2006b, p. 413)

Portanto, o Direito Internacional Humanitário, ao buscar mitigar os danos aos não combatentes, durante e após os conflitos armados, conta com ramificações como o Desarmamento Humanitário, que, nas últimas décadas, passou a ser desenvolvido por meio de Convenções específicas visando a correção de lacunas e adequando-se a um novo momento, com novas perspectivas no cenário internacional.

\subsection{Desarmamento Humanitário: Convenção sobre Munições Cluster}

As discussões, sejam nacionais ou internacionais, sobre desarmamento e controle de armas, evocam desafios e polêmicas intensas. Ainda que o desarmamento completo tenha sido proposto reiteradamente pelas Nações Unidas desde a Resolução nº 1.378 (XIV), de 20/11/1959, a opção mais viável seria, para Rodrigo More, o controle de armas e/ou desarmamento parcial (MORE, 2007). Esta dificuldade aparece uma vez que as armas são um recurso de demanda crescente.

Hedley Bull (2002) denomina como desarmamento forte aquele que seria total e que tornaria a guerra impossível; e o desarmamento fraco 
aquele que teria a máxima redução de armas que acabaria por tornar a guerra menos provável. Bull diz que não existe um nível de confiança suficientemente forte entre os Estados que permita a renúncia total às armas sem colocar em risco a própria segurança dos Estados. Ademais, ele adverte que a eficácia e o funcionamento do desarmamento geral e completo estariam vinculados à existência de uma autoridade mundial que exerceria a verificação e a manutenção das obrigações, inclusive coercitivamente. Bull parte da premissa de que deve haver desigualdade entre Estados para haver equilíbrio de poder e, consequentemente, a paz.

No entanto, More vincula a questão armamentista com a econômica, e entende que, para o desenvolvimentismo, o desarmamento completo seria interessante para um país que esteja enfrentando dificuldades financeiras. Ele alega que:

\footnotetext{
$\mathrm{Na}$ roda-viva do chamado "mercado" [...] os países em desenvolvimento sofrem com a escassez de investimentos e com a demanda sempre crescente por armas, cada vez mais avançadas e destrutivas. O desarmamento geral e completo, com garantias de segurança e defesa coletiva, surge como uma opção economicamente interessante quando escasseiam os recursos. O objetivo é evitar o exemplo da ex-URSS, que se entregou à corrida armamentista pagando o custo do empobrecimento de seu povo, até a declarada ruína econômica em 1989. Armar-se e manter os níveis de desenvolvimento são, como demonstra o exemplo histórico, incompatíveis (MORE, 2007, p. 392).
}

Neste sentido, ainda que haja argumentos para um desarmamento completo, os Estados normalmente se vinculam mais à teoria de Bull e preferem não arriscar este processo. Contudo, um novo enfoque da questão desarmamentista começa a ganhar voz, com os processos de Desarmamento Humanitário (DOCHERTY, 2010).

Os processos de Desarmamento Humanitário emergem por volta dos anos 1990, em um contexto de mudanças tanto estruturais, na organização e polaridade do cenário internacional, quanto nos meios acadêmicos. Os estudos das relações internacionais, especialmente acerca da segurança, 
paz, conflitos e Direito Internacional, passam por importantes ampliações em seus entendimentos e agendas.

As características dos conflitos, nesse momento, também passam por uma mudança no nível de análise. Kaldor (2007) diferencia as chamadas "Novas Guerras" das "Velhas Guerras" em relação aos atores envolvidos, objetivos, formas de financiamento e, mais importante para esta análise, ao método das guerras. Se nas velhas guerras a batalha corpo a corpo era decisiva e a ação das tropas militares de suma importância, as novas guerras se utilizam de outros meios: conquista de territórios por meios políticos, controle da população, deslocamento de pessoas, e especialmente a violência dirigida aos civis, não mais direta e unicamente a tropas inimigas (KALDOR, 2013).

As chamadas Novas Guerras, ao contrário do que o nome sugere, já ocorriam anteriormente. Entretanto, os instrumentos e teorizações apresentados pelo pensamento realista, hegemônico durante a Guerra Fria, não permitiam um entendimento e análise de conflitos mais complexos, para além do nível estatal. Como aponta Docherty (2010),

[...] [t]he post-Cold War era saw a changed perception of armed conflict that influenced the development of humanitarian disarmament treaties. With the fall of the Soviet Union, the threat of mass casualties from a single attack with a weapon of mass destruction diminished. Real-life suffering of individual civilians caused by conventional weapons, such as that documented in the Balkans, Afghanistan, and Iraq, came increasingly into public view. The attention of the international community, therefore, turned to controlling conventional weapons (DOCHERTY, 2010, p. 10).

A divisão em três tipos de desarmamento, apontadas por Docherty (2010), ilustra bem o modo que essas mudanças refletem no surgimento dos processos de Desarmamento Humanitário. A autora classifica os tratados de desarmamento em securitários, híbridos e humanitários. Os dois primeiros caracterizam-se por ter suas bases formuladas ainda na ordem bipolar da Guerra Fria, com um pensamento estatal-militar ligado à lógica realista das Relações Internacionais. A formulação desses tratados reflete a preocupação 
hegemônica no momento de suas negociações, que buscava a manutenção do que Galtung (1969) denomina paz negativa, baseada na ausência de violência.

O desarmamento híbrido pode ser exemplificado pela 'Convenção sobre Certas Armas Convencionais' de 1980. Mesmo que nela prevaleça um pensamento tradicional, extremamente influenciado pelas tensões da Guerra Fria, essa convenção, especialmente em seus Protocolos subsequentes, começa a apresentar preocupações humanitárias importantes. Seu caráter tradicional, entretanto, prejudica o andamento e profundidade nesse sentido, principalmente pelo fato de suas negociações exigirem consenso, o que impede que pautas com fundo humanitário, como a abolição de armas que vitimizam majoritariamente civis, sejam incluídas na versão final (DOCHERTY, 2010).

Buscando a promoção do Direito Internacional Humanitário, e na tentativa de superar a inviabilidade ao tratar do tema na 'Convenção sobre Certas Armas Convencionais', realizada no escopo da ONU, campanhas originadas no seio da Sociedade Civil Global, buscando marcos regulatórios internacionais mais centradas na proteção do ser humano e menos orientadas pelo viés da estratégia das lentes da defesa, pressionaram a favor da necessidade do desarmamento, por mecanismos de resolução de problemas humanitários mais eficazes. É o caso da 'Campanha Internacional pelo Banimento das Minas Terrestres e da Coalizão contra Munições Cluster', atores que impulsionaram a formulação e negociação respectivamente do 'Tratado de Erradicação de Minas Terrestres e da Convenção sobre Munições Cluster'.

Ambos os tratados trazem um entendimento mais ampliado sobre segurança, que passa a ter foco nas populações e indivíduos, não mais puramente nos Estados. Nesse sentido, a 'Convenção sobre Munições Cluster', em seu Artigo $2^{\circ}$ inova ao apresentar a definição de vítimas, entendendo-se pelo termo 
[...] todas as pessoas que perderam a vida ou sofreram um dano físico ou psicológico, uma perda econômica, marginalização social ou um dano substancial na realização de seus direitos devido ao emprego de munições cluster. A definição inclui aquelas pessoas diretamente afetadas pelas munições cluster, assim como os familiares e comunidades prejudicados.

Além disso, o Artigo $5^{\circ} \mathrm{diz}$ respeito à assistência às vítimas, em conformidade ao Direito Internacional Humanitário e ao Direito Internacional dos Direitos Humanos. Discorre tanto a respeito das reparações físicas e materiais quanto à assistência psicológica, apresentando uma série de medidas a serem seguidas por parte dos Estados Partes envolvidos, buscando a reinserção social e econômica das populações e indivíduos afetados pelo uso desse armamento, bem como de seus remanescentes.

Ademais de evitar a violência direta por meio de uma paz negativa, tais processos de desarmamento humanitário passaram a focar tanto na eliminação das ameaças humanitárias durante o período da guerra, quanto nas limitações e constrangimentos físicos, estruturais e materiais do pósconflito. Nessas Convenções, nota-se uma preocupação relativa aos danos inaceitáveis dirigidos especialmente aos civis por consequência do uso indiscriminado de determinadas armas, à recuperação pós-conflito dos locais onde tais armas foram utilizadas, à redução dos danos socioeconômicos, bem como à proteção das populações afetadas.

O Desarmamento Humanitário, nesse sentido, usa de instrumentos legais para reduzir o sofrimento de indivíduos em tempos de guerra e exige dos Estados que forneçam ajuda às vítimas desses conflitos (DOCHERTY, 2010). Busca-se, dessa forma, reduzir a violência estrutural que impede o ir e vir de civis, o cultivo de alimentos, e, de modo geral, o desenvolvimento de atividades essenciais para a sobrevivência de pessoas, grupos e populações. Ressalta-se que nas bases desses processos está a Sociedade Civil Global, atuando como agente transformador das dinâmicas internacionais em prol das vítimas. 


\subsection{Sociedade Civil Global: Subalternidades e Emancipação}

Segundo Schumpeter (1942), a tradição democrática moderna fez com que se consolidasse uma luta competitiva pelo voto popular, articulando, assim, o núcleo do modelo elitista da democracia, que seria o único sistema apropriado para as condições sociais modernas. $\mathrm{O}$ autor alega que o único impulsor do sistema político é o poder, e isso acarreta na situação de que, para que os interesses de uma determinada classe sejam representados, a luta pelo poder tem de acontecer. Em contrapartida, os teóricos liberais veem o respeito aos direitos individuais e o princípio de neutralidade política como uma norma para a legitimidade nas democracias constitucionais. Isto posto, uma sociedade onde se proliferam as exigências dos direitos individuais não pode ser uma comunidade solidária, mas deve ser alienada, anômica, privatizada, competitiva e carente de substância moral (COHEN et al., 2001, p. 29).

Não obstante, manifestou-se um novo agente com um caráter de emancipação, a Sociedade Civil Global. São suas representações as Organizações Não-Governamentais (ONGs); movimentos sociais transnacionais; atores não estatais; agentes independentes de soberania; ativistas além-fronteiras, entre outras (VIEIRA, 2015).

Neste caráter de emancipação, há uma tendência de que os atores das sociedades políticas, para que se mantenham legítimos, devem promover a construção de instituições democráticas na própria sociedade civil, ainda que isso aparente aumentar o número de demandas sociais, pois quando há em um país uma sociedade civil organizada, há uma garantia de uma organização política democrática estável, ou seja, uma garantia contra o domínio permanente feito por qualquer grupo na perspectiva elitista e contra o surgimento de movimentos fundamentalistas e de ideologias antidemocráticas. (COHEN et al., 2001, p. 37). 
Tocqueville já dizia que sem a participação ativa por parte dos cidadãos em instituições igualitárias e em associações civis, não haveria como conservar o caráter democrático da cultura política ou das instituições sociais e políticas. Neste sentido, a sociedade civil moderna está atrelada a princípios igualitários, à inclusão universal e à experiência na articulação da vontade política e da tomada de decisões coletiva, que é de importância primordial para a reprodução da democracia. Assim, os movimentos sociais para a expansão dos direitos, para a defesa da autonomia da Sociedade Civil Global e para sua maior democratização são os que mantêm viva uma cultura política e democrática (COHEN et al., 2001, p. 38), pois os movimentos sociais, com base na sociedade civil, têm o condão de construir uma opinião pública mundial qualificada com maior transparência e crítica em favor de ideais emancipatórios (VIEIRA, 2015).

A democracia, pois, acaba se consolidando como um fator essencial para que a sociedade civil possa ter voz. Percebe-se que movimentos como o Occupy Wall Street, originados por parte dela, acontecem em países com tradições democráticas mais densas e com grau de escolaridade e nível de justiça social mais satisfatório em relação aos demais países do planeta (VIEIRA, 2015).

Por conseguinte, a influência da Sociedade Civil Global acaba levando à consolidação de tratados e itens na agenda de governantes que antes não eram pensados pela comunidade internacional, como a busca pelo controle de armas pequenas e ligeiras no Tratado sobre o Comércio de Armas. Segundo Ballestrin (2010), compreende-se a Sociedade Civil Global como um ator contemporâneo, com características próprias e que entra em conflito diretamente com aqueles que compõem a realidade, como aconteceu com campanhas mundiais feitas por esse ator para pressionar os Estados à adoção do Protocolo de Kyoto (1997) e do Tratado de Ottawa (1997), bem como a participação direta das ONGIs (organizações não-governamentais internacionais) nas conferências mundiais promovidas pelas Nações Unidas. 
Decorrente de uma iniciativa em 2007 por parte da Noruega e de organizações da Sociedade Civil Global, lideradas pela Coalizão Contra Munições Cluster, verifica-se que a Convenção de Oslo, ao aproveitar o caminho aberto pelo Processo de Ottawa, reinventou o nível de consulta e cooperação entre Estados, ONGs e Comitê Internacional da Cruz Vermelha de uma forma original (MASLEN, 2004). Esse papel é inclusive reconhecido no preâmbulo da Convenção, que enfatiza

[...] o papel desempenhado pela consciência pública no fomento dos princípios humanitários, como evidenciado pelo manifesto global para colocar fim ao sofrimento de civis causado pelas munições cluster, e reconhecendo o esforço que com essa finalidade desempenhou a Organização das Nações Unidas, o Comitê Internacional da Cruz Vermelha, a Coalizão Contra as Munições Cluster e outras numerosas organizações não governamentais de todo o mundo (CONVENÇÃO SOBRE MUNIÇÕES CLUSTER, 2008).

Nesse ponto, faz-se importante ampliar o entendimento sobre Sociedade Civil Global. Kaldor (2003, p. 590) sintetiza tal ator como uma plataforma com uma pluralidade de agentes, onde se discutem, fazem campanha e negociam-se temas e ajustes que irão moldar os desenvolvimentos globais, havendo nela três vertentes: uma versão ativista, uma neoliberal e uma pós-moderna. As duas últimas têm destaque por receberem diversas críticas, respectivamente por facilitar reformas para o mercado e propagar o modelo de democracia ocidental - majoritariamente composto por ONGs do Norte global -, e ser caracterizada por grupos nacionalistas e fundamentalistas.

Já a versão ativista é composta por movimentos sociais e redes de ativismo transnacional por causas específicas como minas terrestres, direitos humanos, mudanças climáticas etc., tendo grande impacto na construção de um "regime humanitário". A institucionalização de alguns desses movimentos em ONGs reflete a necessidade de um certo "status" para se obter aceitação e voz internacionalmente. 
Para a autora, a sociedade civil global nasce como uma resposta à guerra, porque a problematizou, debateu e discutiu. Keane (in. Ballestrin, 2010, p. 97), em contrapartida, argumenta que ela “[...] sozinha é incapaz de construir a paz no mundo através de seus próprios esforços [...] e acaba por alimentar as mesmas estruturas que deseja combater". Isto posto, percebe-se que a Sociedade Civil Global tem dificuldades para se consolidar como um agente legítimo.

Críticas mais amplas dirigidas à Sociedade Civil Global direcionam-se também a essa acepção ativista, tanto pela falta de accountability e legitimidade deste grupo, por ser muitas vezes desigual e reforçar os interesses do Norte, quanto por não contestar a legitimidade como um todo dos regimes. Em contrapartida, reconhecendo-se as ambiguidades e fragilidades desse ator, em determinados espaços é perceptível um potencial de redução da insuficiência democrática na governança nacional e internacional, bem como a ampliação das vozes dos grupos afetados, o aumento da transparência, da prestação de contas, e consequentemente, da legitimidade em sua atuação (BUDINI, 2010) - elementos que permitem um entendimento da Sociedade Civil Global como emancipatória, especialmente nas questões de desarmamento humanitário e controle de armas.

Nesse sentido, percebe-se nos processos de Desarmamento Humanitário a emancipação proposta por Ken Booth (1991), autor que aponta a "sociedade civil global embrionária" como essencial para a implementação de uma estratégia emancipatória. No mesmo sentido, Mutua (2000) destaca como um elemento importante das TWAIL sua busca pela vocalização de atores não-estatais, não-governamentais, pobres rurais e urbanos, que conformam majoritariamente o Terceiro Mundo. Busca, portanto, democratizar a governança interna e internacional, trazendo o empoderamento dos subalternos como essencial para uma mudança efetiva da realidade internacional. 
É relevante reforçar que apesar da ampliação e aprofundamento do entendimento acerca da Segurança e do Direito Internacional, estas áreas permanecem majoritariamente dominadas por uma lógica estato-cêntrica e militar, o que dificulta que questões humanitárias sejam pautadas, especialmente em âmbito nacional. Atores como a indústria armamentista e setores militares detêm mais voz e influência nas tomadas de decisões da política nacional que representantes da Sociedade Civil Global, demonstrando, em certa medida, a subalternidade desses últimos, decorrente de uma resistência à visões mais críticas das Relações Internacionais.

Em resposta a isso, percebe-se um crescente papel das redes de ativistas, tanto na proposição de normas, quanto na pressão e monitoramento para o êxito de suas pautas (BUDINI, 2010). Keck e Sikkink (1998), citados por Cohen (2003), descrevem um "efeito bumerangue", referindo-se a articulação transnacional de organizações da sociedade civil, buscando superar a supressão de suas vozes internamente e promover uma "alavancagem" de suas demandas por meio de pressão internacional. Essa triangulação permite a vocalização de populações locais e subalternizadas, que passam a refletir capacidades de transformação e emancipação anteriormente dificultadas.

No âmbito do Desarmamento Humanitário e controle de armas, alguns exemplos são a Campanha Internacional pelo Banimento de Minas Terrestres (ICBL), a Coalizão contra Munições Cluster (CMC) e a Coalizão pelo Controle de Armas (Control Arms), articulações nesse modelo que obtiveram êxito ao pressionar pela formulação de acordos internacionais com fortes aspectos humanitários, grande participação da sociedade civil na proposição, negociação e monitoramento, ademais de obter ampla e célere adesão dos Estados. 


\section{Conclusão}

As abordagens críticas de Relações Internacionais e do Direito Internacional têm depurado as lentes pelas quais a faticidade pós-nacional é lida e interpretada, criando espaços, metodologias e processos cada vez mais inclusivos àqueles atores até então subalternizados por estruturas políticojurídicas pouco comprometidas com a democracia, a paz e os direitos humanos.

Os novos movimentos que orientam a marcha e os desafios das Relações Internacionais e do Direito Internacional são múltiplos e não necessariamente convergentes. Entretanto, uma das direções consistentemente trilhadas diz respeito a humanização de seus conteúdos, que não exclui o caráter estatocêntrico, mas inclui, e por vezes até impõe, o enfrentamento das razões humanas e dos sentidos públicos de suas existências. Novos conteúdos que também têm trajetórias singulares e, potencialmente, pavimentadores de caminhos inclusivos à Sociedade Civil Global.

É na esteira destas inovações que o Direito Internacional do Desarmamento Humanitário emerge, buscando a proibição de certas categorias de armamentos e o controle sobre transferências de armas, para que os não combatentes possam caminhar sem medo de pisar numa mina terrestre, mesmo que o conflito tenha acabado há décadas, que as crianças não corram o risco de se encantar com um artefato disperso que na realidade é uma sub-munição explosiva, ou que se torne proibido transferir armas onde se sabe que serão utilizadas para crimes contra humanidade ou para graves violações de direitos humanos.

Contudo, é evidente que tais processos não teriam futuro sem uma atuação concertada e sistemática da Sociedade Civil Global, que já se mostrou ator chave para negociação e implementação de tratados que se tornaram divisor de águas no Direito Internacional Humanitário, como é o 


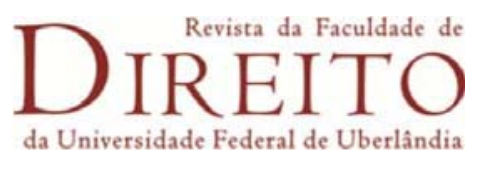

desafio imposto no novo Tratado sobre a Proibição de Armas Nucleares, cuja coalizão da sociedade civil engajada, ICANW, teve atuação reconhecida pelo Nobel da Paz de 2017.

Quanto ao Brasil, os desafios postos estão claros. Até que ponto estaremos dispostos a marchar na contramão dos progressos humanitários pela produção e exportação de munições cluster (armas que estão em franco processo de erradicação)? Quais poderiam ser os caminhos para termos mais e melhores canais de interação entre Sociedade Civil e Diplomacia? Qual o sentido das forças políticas do Congresso Nacional emperrarem a tramitação do Tratado sobre Comércio de Armas? E, por fim, o que falta para que a República Federativa do Brasil se torne parte da Convenção sobre Munições Cluster?

\section{Referências}

BACHAND, Rémi. Les Subalternes et le Droit International: une critique politique. Paris: A. Pedone, 2018.

BALLESTRIN, Luciana. Com quantas armas se faz uma Sociedade "Civil"?: controles sobre armas de fogo na governança global, Brasil e Portugal (1995-2010). Tese (Doutorado em Ciência Política) - Universidade Federal de Minas Gerais. Belo Horizonte: UFMG, 2010.

BUDINI, Terra Friedrich. Reflexões sobre a ideia de sociedade civil global e a ação política não-estatal além das fronteiras. Dissertação (Mestrado em Relações Internacionais) - Pontifícia Universidade Católica de São Paulo. São Paulo: PUCSP, 2010.

BULL, Hedley. A Sociedade Anárquica. Trad. Sergio Bath. Brasília: UnB, IPRI; São Paulo: Imesp, 2002.

CAMERON, Maxwell; LAWSON, Robert; TOMLIN, Brian (editors). To Walk Without Fear: the global movement to ban landmines. Oxford: Oxford University Press, 1998.

CANÇADO TRINDADE, Antônio Augusto. A Humanização do Direito Internacional. Belo Horizonte: Del Rey, 2006a.

. Desafios e Conquistas do Direito Internacional dos Direitos Humanos no Início do Século XXI. Curso de Direito Internacional Organizado pela Comissão Jurídica Interamericana da OEA. Rio de Janeiro, 2006b. Disponível em: https://www.oas.org/dil/esp/407490\%20cancado\%20trindade\%200EA\%20CJI\%20\%20.def.pdf. Acesso em 11 out. 2018.

CHIMNI, B. S. Third World Approaches to International Law: A Manifesto. International Community Law Review, v. 8, pp. 3-27, 2006.

COHEN, Jean L.; ARATO, Adrew. Sociedad Civil y Teoría Política. México: Fondo de Cultura Económica, 2001. 


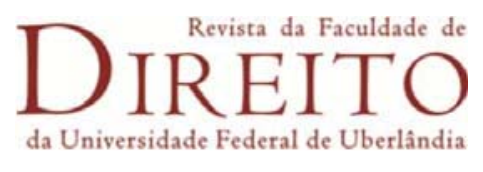

CONTROL ARMS. Our Work in 2018. s./l, 2018. Disponível em: https://controlarms.org/control-arms/. Acesso em: 28 out. 2018.

DEL'OLMO, Florisbal de Souza. Curso de Direito Internacional Público. Rio de Janeiro: Forense, 2006.

DOCHERTY, Bonnie. Ending Civilian Suffering: The Purpose, Provisions, and Promise of Humanitarian Disarmament Law. Austrian Review of International and European Law, v. 15, p. 744 et seq., 2010.

DUPUY, Pierre-Marie. L'unité De L'ordre Juridique International. Cours general de droit international public - Académie de Droit International de La Haye. Recueil des cours, v. 297. Hague: BRILL, 2002.

GALINDO, George Rodrigo Bandeira. A volta do terceiro mundo ao direito internacional. Boletim da Sociedade Brasileira de Direito Internacional, v. 11924, p. 46-68, 2013.

GALTUNG, Johan. Violence, peace and peace research. Journal of Peace Research, v. 6, n. 3, pp. 167-191, 1969.

HAUG, Hans. Humanity for all: the international red cross and red crescent movement. Berna: Henry Dunant Institute/Hupt, 1993.

ICBL-CMC. Strategy 2017-2021. s./l., 2017. Disponível em: http://www.stopclustermunitions.org/media/2397469/Strategy-2017-2021-English-Final.pdf. Acesso em: 28 out. 2018.

KALDOR, Mary. The idea of global civil society. International affairs, v. 79, n. 3, p. 583593, 2003.

New \& Old Wars. Stanford University Press, 2. ed. p. 92118, 2007.

In Defence of New Wars. Stability, p. 116, 2013.

KRAUSE, Keith. ed. Small Arms Survey 2015: Weapons and the World. Cambridge University Press, 2015.

MORE, Rodrigo Fernandes. Direito Internacional do Desarmamento: O Estado, a ONU e a Paz. Lex Editora S.A, 2007.

MUTUA, Makau. What is Twail? The American Society of International Law: Proceedings of the 94th Annual Meeting, Washington DC, 2000.

PNUD. Informe sobre desarrollo humano 1994. México: Fondo de cultura económica, 1994.

RAJAGOPAL, Balakrishnan. International Law and Social Movements: Challenges of Theorizing Resistance. Columbia Journal of Transnational Law, v. 41, n. 2, pp. 397 434, 2003.

REZEK, Francisco. Direito Internacional Público: Curso Elementar. 16. ed. São Paulo: Saraiva, 2016.

SASSÒLI, Marco; BOUVIER, Antonie A. How does law protect in war? Cases, documents and teaching materials on contemporary practice in international Humanitarian Law. Genebra: CICV, 1999.

SCHUMPETER, Joseph. Capitalism, Socialism, and Democracy . New York, Harper \& Row, 1942.

VIEIRA, Gustavo Oliveira. Inovações em Direito Internacional: um estudo de caso a partir do Tratado de Ottawa. Santa Cruz do Sul: Edunisc, 2006. 
VIEIRA, Gustavo Oliveira; SITO, Santiago Artur Berger (Org.) . O Tratado Banindo as Bombas Cluster e a Posição Brasileira: para qualificar o debate nacional. Santa Maria: Unifra, 2010. v. 1. 168p

VIEIRA, Gustavo Oliveira. Constitucionalismo na Mundialização: Desafios e Perspectivas da Democracia e dos Direitos Humanos. Coleção direitos humanos e democracia. Ijuí: Unijuí, 2015.

WILLIAMS, Jody; GOOSE, Stephen; WAREHAM, Mary (editors). Banning Landmines: disarmament, citizen diplomacy and human security. Lanham: Rowman \& Littlefield, 2008.

WILLIAMS, Paul D. Security Studies: An Introduction. Routledge, 2012. 